\title{
Neuropathology of AIDS: An Autopsy Review of 284 Cases from Brazil Comparing the Findings Pre- and Post-HAART (Highly Active Antiretroviral Therapy) and Pre- and Postmortem Correlation
}

\author{
Ana Cristina Araújo Lemos Silva, ${ }^{1}$ Blenda Sousa Carli Rodrigues, ${ }^{2}$ \\ Adilha Misson Rua Micheletti, ${ }^{1}$ Sebastião Tostes Jr., ${ }^{3}$ Antonio Carlos Oliveira Meneses, ${ }^{1}$ \\ Mário Leon Silva-Vergara, ${ }^{4}$ and Sheila Jorge Adad ${ }^{1}$ \\ ${ }^{1}$ Discipline of Special Pathology, Universidade Federal do Triângulo Mineiro (UFTM), Avenida Getúlio Guaritá 130, \\ 38025-440 Uberaba, MG, Brazil \\ ${ }^{2}$ Scientific Initiation Scholarship, Conselho Nacional de Desenvolvimento Científico e Tecnológico (CNPq), UFTM, \\ 38025-440 Uberaba, MG, Brazil \\ ${ }^{3}$ Discipline of Forensic Medicine, UFTM, Avenida Getúlio Guaritá 130, 38025-440 Uberaba, MG, Brazil \\ ${ }^{4}$ Discipline of Infectious and Parasitic Diseases, UFTM, Avenida Getúlio Guaritá 130, 38025-440 Uberaba, MG, Brazil \\ Correspondence should be addressed to Sheila Jorge Adad, sheila.adad@gmail.com
}

Received 7 November 2011; Accepted 13 December 2011

Academic Editor: Magnus Gisslén

Copyright ( 12012 Ana Cristina Araújo Lemos Silva et al. This is an open access article distributed under the Creative Commons Attribution License, which permits unrestricted use, distribution, and reproduction in any medium, provided the original work is properly cited.

A retrospective study of central nervous system (CNS) in 284 autopsy AIDS cases in Brazil (1989-2008) divided into 3 groups: A (without antiretroviral treatment: 163 cases); B (other antiretroviral therapies: 76 cases); C (HAART for 3 months or more: 45 cases). In 165 (58.1\%) cases, relevant lesions were found, predominantly infections $(54.2 \%)$; the most frequent was toxoplasmosis $(29.9 \%)$ followed by cryptococcosis $(15.8 \%)$, purulent bacterial infections $(3.9 \%)$, and HIV encephalitis (2.8\%); non-Hodgkin lymphomas occurred in $1.4 \%$ and vascular lesions in $1.1 \%$. There was no difference when compared the frequency of lesion among the groups; however, toxoplasmosis was less common while HIV encephalitis was more frequent in group C related to A. CNS lesions remain a frequent cause of death in AIDS; however, the mean survival time was four times greater in group C than in A. In 91 (55.1\%) of 165 cases with relevant brain lesions (or 32\% of the total 284 cases), there was discordance between preand postmortem diagnosis; disagreement type 1 (important disease that if diagnosed in life could change the patient prognosis) occurred in $49(53.8 \%)$ of 91 discordant cases (17.6\% of the total 284$)$ indicating the autopsy importance, even with HAART and advanced diagnostics technologies.

\section{Introduction}

The CNS is the second most-affected organ in AIDS, second only to the lung [1-4]. The immunity deficiency triggered by HIV favors the development of infections by opportunistic agents, being Toxoplasma gondii, Cryptococcus neoformans, and cytomegalovirus the most common in CNS [5-8]; regarding cancer predominates primary non-Hodgkin lymphomas [2, 9]. HIV-specific lesions appear, in general, later in the evolution of the disease, with giant multinucleated cells often found, considered to be "pathognomonic" of HIV infection in CNS $[10,11]$. Necropsy is an important method to understand not only the natural course of a disease, but it also enables, through acquired knowledge, a better clinical approach in providing patients with early diagnosis, better management of patients with AIDS, and the election of a prevention option $[3,8]$. Necropsy is also a valuable tool for recognizing clinically undiagnosed infections and 
malignant neoplasms [12-14]. However, systematic studies of autopsy series from HIV-positive patients evaluating the neuropathological findings are infrequent and most have evaluated the pre-HAART period $[4,5,7,9,15-18]$ and even scarcer are post-HAART studies $[2,3,19-23]$, perhaps because there was an important reduction in the number of autopsies from HIV-positive patients [3, 19, 21, 22]. However, they remain important even after HAART, as changes occurred after that therapy, such as a decrease in opportunistic infections and the increase of HIV encephalitis [24], at least in developed countries, although in the rest of the world, in over $90 \%$ of AIDS cases, patients do not survive long enough to present HIV neurological complications [25]. However, these autopsy studies are even rarer in developing countries, which makes it difficult to establish the true prevalence of the neuropathological lesions [26]. The importance of these studies can be felt when analyzing the frequencies of some diseases, for example, tuberculosis meningitis, which was seen in $12 \%$ of HIV autopsies in India [16], similar frequency to that found in Africa (11\%), while in the USA occurred in only $1.4 \%$ of cases [27]. Though, we found no comparative study of CNS findings before and after HAART on autopsy series in developing countries (through Medline search).

Among the autopsy series that analyzes changes in the CNS pre- and post-HAART, Masliah et al. [3] compared the frequency of lesions per year for 15 years (1982 to 1998), but they did not separate those cases by groups and do not mention how many did or did not use HAART. It was observed a decrease in opportunistic infections and an increase of HIV encephalitis in the last years of the study. Jellinger et al. [2] and Morgello et al. [20] separated into three periods, according to the therapeutic regimen at the time, but did not evaluate data regarding the use of HAART. Neuenburg et al. [21] and Vago et al. [22] divided the years researched into four periods, the last one corresponding to the HAART period; in the Neuenburg et al. [21] study only $24(57 \%)$ of 42 patients from this last period were using such medication and Vago et al. [22] found $96(90.6 \%)$ of 106 patients using HAART, but do not refer for how long. Gray et al. [19] evaluated 23 cases of autopsies who received HAART for at least 3 months before death, and Walsh et al. [23] evaluated 11 cases in the post-HAART era, however, 2 never used such medication and only $2(12.5 \%)$ used HAART more than 3 months without interrupting the use of more than 2 months before death. This last study, although in a small series, shows that relying only on the time of autopsy, as occurred in most studies, may not reflect the reality on the use of medication. These data are important because there is an initial rapid increase in CD4 counts in the first 3 months of therapy, although still generally increasing more slowly in subsequent years [28], observing a significant improvement of immunity in the first 3-6 months [29], and do not use HAART for more than 2 months characterizes abandonment with loss of the medication benefit [30].

Wilkes et al. [14] highlight the value of autopsy in AIDS to the correlation between pre- and postmortem. From 101 autopsies evaluated, $74 \%$ cases of AIDS-related illnesses were not suspected clinically, such as cytomegalovirus (49\%), fungal systemic (20\%), Kaposi's sarcoma (14\%), mycobacteriosis $(11 \%)$ and CNS lymphoma (4\%). Comparison of pre- and postmortem findings in AIDS was also performed by Antinori et al. [31] in 1630 autopsies, between 1984 and 2002, divided into four periods according to the use of antiretroviral therapy; however, only invasive fungal infections were evaluated. They found invasive fungal infections in 297 cases, which $54.2 \%$ were not suspected clinically, with no variation in percentage over the periods. In 38 (36.9\%) of 103 cases in which mycosis was the main disease, the diagnosis was not suspected premortem, and in $17(45 \%)$ of these 38 cases, the error would be Goldman's type I. This study confirms the value of autopsy in AIDS patients, even in the HAART era.

The objectives of this study were to characterize CNS lesions in AIDS autopsies over 20 years, according to antiretroviral therapy, to assess whether there were changes in the pattern of lesions and in survival time among the study groups and if relevant lesions to death were suspected clinically.

\section{Material and Methods}

This study was approved by the Research Ethics Committee from the Federal University of Triângulo Mineiro (number 831). It is a retrospective study of consecutive autopsies from HIV-positive patients (minimum time of hospitalization 24 hours) performed in a teaching hospital in Uberaba, MG, Brazil, from January 1989 to December 2008. From 1989, we adopted a systematic collection of blood from all autopsy cases, to conduct HIV testing. Clinical reports obtained from medical records and autopsy requests were written in a form, registering all clinical hypotheses made to the CNS, use or not of antiretroviral therapy (type and duration of use), survival time after HIV infection diagnosis, cause of death stated in the autopsy report and morphological data from all organs obtained in the autopsy report, and adding CNS microscopic review, in all cases, by the author of this study. Data concerning CD4 cell count (absent in 16.5\% of cases) and viral load (which only began to be routinely performed in our institution from 2000) were not systematically analyzed in the present study, although eventually in existing cases, they were useful for eventual consideration of immunodeficiency.

The standardization sample for microscopy of the CNS in autopsies of our service is a minimum of three tissue blocks with sample from different lobes (one block), basal ganglia and hippocampus (one block), midbrain, pons, and cerebellum (one block); additional blocks were taken from macroscopic lesions. Paraffin sections $(5 \mu \mathrm{m})$ were stained with hematoxylin-eosin and, where appropriate, special staining techniques were carried out for microorganisms and demyelinating disease assessment (Gram, Grocott, Mucicarmin, Schiff's periodic acid, Fite Faraco, Luxol Fast Blue). Immunohistochemical reaction (polymer technique) was made in some cases using monoclonal antibodies for toxoplasma (Novocastra-NCL-TG-TP3), cytomegalovirus (NovocastraNCL-CMV-pp65), herpes virus (Dako HSV-I and II), JC virus (Novocastra-NCL-JCBK) and for characterization of 
lymphoma: CD3 (Dako-CD3-Leu, T3), CD20 (Novocastra, NCL-CD20-L26), CD 30 (Dako-CD30 Ber-H2), CD45 (Dako CD45RO-UCHL1), CD45-LCA (Dako CD45, LCA2B11 + PD7/26). In situ hybridization for Epstein Barr was performed in three cases of non-Hodgkin lymphoma.

The cases were divided into three groups: (A) without any antiretroviral medication; (B) use of 1 or 2 antiretrovirals for any period of time, HAART for less than 3 months or abandoned the use of HAART for more than 2 months; (C) patients on HAART for 3 months or more. During the review of the medical records, it was registered when HIV infection diagnosis was made and the date of death, being calculated the survival time in months. Patients whose diagnosis of HIV infection was made at autopsy or during the hospitalization in which death occurred (hospital stay from 1 to 29 days), the survival time was considered zero. All pathological findings found by CNS microscopic review were tabulated, as mentioned earlier. Then, it was assessed whether findings would be important or not, clinically, not considering relevant focal scarring (focal gliosis, mild mononuclear infiltrate in the meninges, mild ependimite, meningeal fibrous thickening), focal/mild hemorrhage, mild edema, or edema resulting from the final event of the death. Next, where significant pathological findings in the CNS, or with evolutive potential, were found we carried out a comparison with the clinical hypotheses, in order to evaluate the pre- and postmortem agreement. For those cases with diagnostic disagreements between the anatomopathological lesions in the CNS and the clinical hypotheses, we used the classification proposed by Goldman et al. [32], simplified by de Almeida et al. [12], separating them as follows: type 1 disagreement: an important disease, which clinically diagnosed might had changed the prognosis; type 2 disagreement: important disease not diagnosed, however, if clinically diagnosed, would not have changed the prognosis; type 3 disagreement: minor disease not diagnosed, with doubtful or no influence on prognosis.

The morphological data from different organs, recorded in the autopsy reports, were used to assist in diagnosis of immunodeficiency (such as, opportunistic infections indicative of AIDS, according to the Centers for Disease Control, CDC, USA, 1993) and also to evaluate the immediate cause of death.

\section{Results}

From January 1989 to December 2008, 1785 autopsies were made in our hospital, and $299(16.7 \%)$ cases showed seropositive for HIV. We excluded 15 of 299 cases: 9 for having no criteria for defining AIDS (according to the Centers for Disease Control, CDC, USA, 1993) and 6 by the absence of CNS histological sections or no medical record found; therefore, 284 AIDS autopsies have been used in this study. Ninety of these 284 cases (autopsies from 1989 to 1996) had already been partly previously analyzed in the author's master's thesis [33], corresponding to the period before the introduction of HAART in our Institution. Eighty (28.2\%) of 284 cases were female; an increase in the percentage of the female population was observed over the years evaluated, which was $17.8 \%$ in the 1989 to 1996 period and increased to 33\% from 1997 to 2008. Regarding age, considering a total of 284 cases, the mean age was $35.7 \pm 10.8$ years (minimum 16 and maximum 69 years). There was a slight increase when comparing the period from 1989 to $1996(34.3 \pm 11.3)$ to the one from 1997 to $2008(36.3 \pm 10.5)$. The main risk factors for HIV infection were drug abuse in $33.1 \%$ (94 of 284 cases; frequency of $37.2 \%$ among 204 male cases and $22.5 \%$ among 80 female cases); homosexuality/bisexuality in $14.1 \%$ (homosexuality/bisexuality in males $19.6 \%$, while in female patients only $1 \%$ ). Among 80 female cases, $22.5 \%$ reported as a risk factor HIV-positive partner, and also $22.5 \%$ reported promiscuity. Several patients reported 2 risk factors and in $27.1 \%$ of 284 cases there was no reference about the risk factor.

The percentage of cases with drug use was slightly lower in the period 1989-1996 in comparison to that from 1997-2008 (35.6\% versus 32\%); yet regarding homosexuality/bisexuality, until 1996 the frequency was much higher than after 1997 (24.4\% versus 9.3\%), which likely results, at least partially, of the increase of AIDS cases in women since 1997 (17.8\% versus 33\%).

Regarding the use of antiretroviral medication, since 1993 some patients were already using monotherapy; however, HAART was introduced in our service from 1997. Although only 90 of the total 284 cases are before 1997, most individuals in this study did not have any antiretroviral treatment, fitting them into group A (163 cases $=57.4 \%)$. The large number of patients without use of antiretroviral is probably due, in part, also to the fact that in $69(24.3 \%)$ cases the diagnosis of HIV infection was made at autopsy (18 cases; minimum time of hospital stay 24 hours) or during hospitalization in which death occurred (maximum length of hospital stay 29 days), represented by 17 (18.9\%) of 90 cases before 1997, and $52(26.8 \%)$ of 194, from 1997. In all 18 cases, whose diagnosis of HIV/AIDS was made only after death, there were opportunistic infections in CNS (toxoplasmosis or cryptococcosis) or in another organs (cytomegalovirus, pneumocystis pneumonia, disseminated mycobacteriosis, or histoplasmosis). These data demonstrate that HIV patients evaluated in this study often sought late medical attention. Of 284 cases, 75 were treated with HAART for some time; however, 30 of these patients had used HAART for less than 3 months or abandoned the treatment for more than 2 months before death. These 30 patients, added to 46 patients who used only one or two antiretroviral constituted group B (76 cases, 26.8\%). Then in group C were only $45(15.8 \%)$ cases.

\subsection{Characterization and Frequency of Morphological Findings} in the CNS According to the Study Groups. In 165 (58.1\%) of 284 - cases relevant brain lesions were identified. Throughout the period and studied groups, infectious lesions (54.2\%) greatly predominated in relation to neoplasms $(2.5 \%)$ and vascular lesions $(1.1 \%)$. The result of these data is presented in Table 1.

As shown in Table 1, toxoplasmosis was the most frequent infection, seen in 85 (29.9\%) of 284 cases, followed by 
TABLE 1: Relevant morphological lesions in the central nervous system in 284 autopsies of patients with acquired immunodeficiency syndrome, according to the study groups.

\begin{tabular}{|c|c|c|c|c|c|c|c|c|}
\hline \multirow[t]{2}{*}{ Type of lesion } & \multicolumn{2}{|c|}{ Group A } & \multicolumn{2}{|c|}{ Group B } & \multicolumn{2}{|c|}{ Group C } & \multicolumn{2}{|c|}{ Total } \\
\hline & $n$ & $\%$ & $n$ & $\%$ & $n$ & $\%$ & $n$ & $\%$ \\
\hline Infections & 97 & $59.5 \%$ & 35 & $46 \%$ & 22 & $48.9 \%$ & 154 & $54.2 \%$ \\
\hline Protozoa & 59 & $36.2 \%$ & 19 & $25.0 \%$ & 8 & $17.8 \%$ & 86 & $30.3 \%$ \\
\hline Toxoplamosis & $* 59$ & $36.2 \%$ & 18 & $23.7 \%$ & $* 8$ & $17.8 \%$ & 85 & $29.9 \%$ \\
\hline Amebiasis & 0 & 0 & 1 & $1.3 \%$ & 0 & 0 & 1 & $0.3 \%$ \\
\hline Fungal & 30 & $18.4 \%$ & 12 & $15.8 \%$ & 7 & $15.6 \%$ & 49 & $17.2 \%$ \\
\hline Cryptococosis & 27 & $16.6 \%$ & 11 & $14.5 \%$ & 7 & $15.6 \%$ & 45 & $15.8 \%$ \\
\hline Histoplasmosis & 2 & $1.2 \%$ & 0 & 0 & 0 & 0 & 2 & $0.7 \%$ \\
\hline Paracoccidioidomycosis & 1 & $0.6 \%$ & 0 & 0 & 0 & 0 & 1 & $0.3 \%$ \\
\hline Sporotrichosis & 0 & 0 & 1 & $1.3 \%$ & 0 & 0 & 1 & $0.3 \%$ \\
\hline Bacterial & $† 8$ & $4.9 \%$ & 3 & $3.9 \%$ & 3 & $6.7 \%$ & $\dagger 14$ & $4.9 \%$ \\
\hline Meningitis/encephalitis/abscess & 5 & $3.1 \%$ & 3 & $3.9 \%$ & 3 & $6.7 \%$ & 11 & $3.9 \%$ \\
\hline Tuberculosis/mycobacteriosis & 4 & $2.4 \%$ & 0 & 0 & 0 & 0 & 4 & $1.4 \%$ \\
\hline Virus & 11 & $6.7 \%$ & 2 & $2.6 \%$ & 6 & $13.3 \%$ & 19 & $6.7 \%$ \\
\hline Cytomegalovirus & 5 & $3.1 \%$ & 1 & $1.3 \%$ & 1 & $2.2 \%$ & 7 & $2.5 \%$ \\
\hline Nodular encephalitis & 2 & $1.2 \%$ & 1 & $1.3 \%$ & 0 & 0 & 3 & $1.2 \%$ \\
\hline HIV & $* 3$ & $1.8 \%$ & 0 & 0 & $* 5$ & $11.1 \%$ & 8 & $2.8 \%$ \\
\hline $\mathrm{JC}$ & 1 & $0.6 \%$ & 0 & 0 & 0 & 0 & 1 & $0.3 \%$ \\
\hline Neoplasms & 6 & $3.7 \%$ & 1 & $1.3 \%$ & 0 & 0 & 7 & $2.5 \%$ \\
\hline Lymphoid Neoplasms & 4 & $2.4 \%$ & 1 & $1.3 \%$ & 0 & 0 & 5 & $1.8 \%$ \\
\hline Meningiomas & 2 & $1.2 \%$ & 0 & 0 & 0 & 0 & 2 & $0.7 \%$ \\
\hline Vascular lesions & 0 & 0 & 1 & $1.3 \%$ & 2 & $4.4 \%$ & 3 & $1.1 \%$ \\
\hline Concomitant Lesions & 11 & $3.9 \%$ & 1 & $0.4 \%$ & 2 & $0.7 \%$ & 14 & $4.9 \%$ \\
\hline Subtotal with relevant lesions & 104 & $63.8 \%$ & 37 & $48.7 \%$ & 24 & $53.3 \%$ & 165 & $58.1 \%$ \\
\hline Subtotal normal or without relevants lesions & 59 & $36.2 \%$ & 39 & $51.3 \%$ & 21 & $46.7 \%$ & 119 & $41.9 \%$ \\
\hline Total & 163 & $100 \%$ & 76 & $100 \%$ & 45 & $100 \%$ & 284 & $100 \%$ \\
\hline
\end{tabular}

Group A: without use of any antiretroviral medication; B: 1 or 2 antiretroviral therapy or HAART for any time less than 3 months; C: HAART for 3 months or more; ${ }^{*} P<0.05 ; \chi^{2}$ test. Nonrelevant lesions occurred in $103(36.3 \%)$ of 284 cases, represented by focal alterations, scarring or just edema related to the final events; in only $16(5.6 \%)$ cases the brain was completely normal. †Among the cases with bacterial infection in group A, one patient showed concomitant infection by coccus and mycobacteria in different regions of the CNS ( 9 bacterial infections/8 patients).

cryptococcosis in $45(15.8 \%)$ cases, purulent bacterial infections in $11(3.9 \%)$ cases, HIV encephalitis in eight $(2.8 \%)$, and cytomegalovirus infection in 7 (2.5\%) cases. Regarding noninfectious lesions, which occurred only in $10(3.5 \%)$ cases, 7 (2.5\%) primitive CNS neoplasms and 3 (1.1\%) vascular lesions were identified. Among the tumors, there were 2 benign (Grade I meningiomas-World Health Organization) and 5 lymphoid malignancies. These were represented by a case of meningeal plasmablastic plasmacytoma and 4 (1.4\%) non-Hodgkin's lymphoma, diffuse type of B cells, associated with Epstein Barr virus infection in all 3 cases this agent was investigated by in situ hybridization. Vascular lesions were represented by a case of subarachnoid hemorrhage in brainstem, a case of acute subdural hematoma and a case of massive intraparenchymal hemorrhage. There was no difference when compared the frequency of lesion among the groups; however, toxoplasmosis was less common while HIV encephalitis was more frequent in group C related to A.

A comparison of neuropathological lesions in 94 drug abusers and 190 nondrug users showed that bacterial infections (including mycobacteria) were more frequent in drug abusers $(9.6 \%$ versus $2.6 \%$, Fisher's exact test, $P=0.01)$. There was no statistically significant difference in relation to other lesions.

3.2. Analysis of the Relationship between Survival Time after Diagnosis of HIV Infection and Use or not HAART. In 261 (90.9\%) of 284 cases there were data on medical records to measure the survival time after diagnosis of HIV infection. Table 2 shows this result, according to the study groups.

As shown in Table 2, the mean survival time in group C (49.1 months) was more than four times that in group A (11.2 months) and almost twice as long in group B (25.8 months), showing clear benefit of HAART.

3.3. Analysis if the Morphological Lesions in the CNS (Postmortem) were Clinically Suspected or not (Premortem). Disagreement was found between the clinical suspicion (premortem) and neuropathological findings at autopsy (postmortem) in 91 (55.1\%) of 165 cases in which significant lesions in the CNS were observed, which represents $32 \%$ 
TABLE 2: Average values of survival time (months) after diagnosis of HIV infection in 261 of 284 autopsies of acquired immunodeficiency syndrome, in which it was possible to obtain this information, according to the study groups.

\begin{tabular}{|c|c|c|c|c|}
\hline Group & $\begin{array}{c}\mathrm{A} \\
N=145\end{array}$ & $\begin{array}{c}\text { B } \\
N=71\end{array}$ & $\begin{array}{c}\mathrm{C} \\
N=45\end{array}$ & $\begin{array}{l}\text { All cases } \\
N=261\end{array}$ \\
\hline Mean & 11.2 & 25.8 & 49.1 & 21.7 \\
\hline Standard deviation & 26.1 & 30.6 & 30.0 & 31.2 \\
\hline Median & 1 & 11 & 48 & 6 \\
\hline Min-max value & 0-192 & $0-132$ & $6-144$ & 0-192 \\
\hline
\end{tabular}

Group A: without use of any antiretroviral medication; B: 1 or 2 antiretroviral therapy or HAART for any time less than 3 months; C: HAART for 3 months or more; min: minimum, max: maximum. $N$ : number of cases it was possible to obtain the survival time. Kruskal-Wallis/Dunn: $P<0.001$ when comparing all groups.

compared to the total of 284 cases. In $49(53.8 \%)$ of these 91 cases, which represent $17.2 \%$ of the total of 284 cases, the disagreement was type 1 , that is, important lesion was not clinically diagnosed (premortem), which could alter the prognosis; this occurred in all lymphoma cases. Regarding the time, the type I error was $62.2 \%$ (23 of 37 discordant cases with significant CNS lesions) until 1996, then decreasing to $48.8 \%$ (26 of 54 discordant cases), probably partly due to knowledge acquired through the study of the autopsies that were reported through anatomoclinical sessions weekly.

In $22(24.2 \%)$ of 91 cases, the disagreement was type 2 , that is, important lesions were not diagnosed clinically (premortem), but even if they did would not change the prognosis; this occurred in several cases of cerebral toxoplasmosis of patients who died due to lung infections by other agents. In $20(22 \%)$ of 91 cases, disagreement was type 3 , that is, less important lesions were not diagnosed clinically (premortem), with doubtful or no influence on prognosis; as an example, we could name meningioma in a patient with respiratory failure due to pneumocystis pneumonia.

\section{Discussion}

Although Brazil is one of the countries with the largest number of AIDS cases (about 600,000 patients) out of Africa, a slightly smaller number than the one estimated for the entire Central and Western Europe [34], this is the first Brazilian study on AIDS autopsy (and also in developing countries) to compare the neuropathological lesions preand post-HAART era and to demonstrate that these lesions are still frequent and are often not diagnosed clinically (premortem). Necropsy is an important tool to understand the lesions in AIDS and several other diseases. However, there has been an increasing reduction in the number of AIDS autopsy, both in our material as in several other studies [19, $21,22]$, probably because the complementary diagnostic and clinical experience have contributed to better management of patients and in obtaining premortem diagnosis.

The percentage of women in our cases has increased over the course of years (from $17.8 \%$ up to 1996 to $33 \%$ after 1996), following the world trend as also observed by Jellinger et al. [2], whose frequency rose from $7.9 \%$ to $29.6 \%$, explaining the differences regarding older studies, such as the Brazilian pre-HAART $[9,18]$. The mean age of AIDS patients in this study (35.7 years), which was lower than in developed countries ranging from 38.4 to 40.5 years [2, 3, 21], probably because survival rate is higher in these countries.

As for the overall frequency of neuropathological findings, we found that in $58.1 \%$ of our 284 cases there were significant morphological lesion; a higher value than that found in the Brazilian clinical study De Oliveira et al. [35], which was $46.5 \%$. This difference probably results from greater easiness to diagnose lesions at the anatomopathological study. However, our percentage was lower than the values obtained by Masliah et al. [3], Morgello et al. [20], Walsh et al. [23], Vago et al. [22], and Neuenburg et al. [21], which ranged from $63 \%$ to $85 \%$. However, if we compute in our study all cases where there was some kind of CNS lesion (relevant or focal lesions and just edema), as some authors, our percentage would be $94.4 \%$, similar to that found by Chimelli et al. [9] in the pre-HAART era, which was $91.3 \%$.

Table 3 shows a comparative summary of various series of autopsies studies pre- and post-HAART, regarding to neuropathological lesions.

Assessing the frequency of all neurological lesions relevant in each group studied, a slightly higher percentage was found in the group without antiretroviral treatment $(63.8 \%)$ than in the other groups $(48.7 \%$ and $53.3 \%)$, although these differences were not statistically significant. This result could give a false impression that HAART did not alter the prognosis in AIDS; however, the survival time of patients clearly shows benefit of this therapy, although in the final stage, the cause of death is often by neuropathological lesions. Our percentage of lesions in groups was smaller than those of Jellinger et al. [2], which decreased from $80 \%$ to $60 \%$. It is possible this higher percentage elapses from the larger CNS sample assessed by these authors, or from not relevant lesions that might have been also computed. Unfortunately, in our study the number of cases of group C was small, perhaps indicating low adherence to HAART in our midst, or possibly because using these drugs makes lower mortality rates, resulting in fewer autopsies, as occurred in several post-HAART studies [2, 19-22]. On the other hand, when we began this study we thought that since 1997 almost all patients would be under regular use of HAART protocol, mainly because these medications are free in Brazil; however, only $23.2 \%$ of 194 cases of this period used HAART for 3 months or more and $44.8 \%$ of these individuals did not use any antiretroviral medication. These data are difficult 
TABLE 3: Comparison between different studies regarding lesions to the central nervous system, in a series of autopsies of patients with HIV infection.

(a)

\begin{tabular}{lcccccccccc}
\hline Pre-HAART & $N$ & Les & Tox & Cry & CMV & HIV & PML & Nod Enc & Lym & Vas \\
\hline Moskowitz et al. 1984 Miami, USA [4] & $\mathbf{5 2}$ & $\mathbf{7 3 . 0}$ & $\mathbf{3 0 . 8}$ & $\mathbf{1 . 9}$ & $\mathbf{3 . 8}$ & $\mathbf{9 . 6}$ & $\mathbf{3 . 8}$ & $\mathbf{7 . 7}$ & $\mathbf{1 . 9}$ & $\mathbf{7 . 6}$ \\
\hline Anders et al. 1986 Los Angeles, USA [5] & $\mathbf{8 9}$ & $\mathbf{7 4 . 0}$ & $\mathbf{6 . 7}$ & $\mathbf{1 2 . 4}$ & $\mathbf{1 5 . 7}$ & $\mathbf{?}$ & $\mathbf{6 . 7}$ & $\mathbf{4 7 . 2}$ & $\mathbf{3 . 4}$ & $\mathbf{1 9 . 1}$ \\
\hline Petito et al. 1986 New York, USA [17] & $\mathbf{1 5 3}$ & $\mathbf{8 0 . 0}$ & $\mathbf{1 0 . 0}$ & $<\mathbf{3}$ & $\mathbf{2 6 . 0}$ & $\mathbf{2 8 . 0}$ & $<\mathbf{3}$ & $\mathbf{1 7 . 0}$ & $\mathbf{6 . 0}$ & $\mathbf{0}$ \\
\hline Budka et al. 1987 Europe [15] & $\mathbf{1 0 0}$ & $\mathbf{9 5 . 0}$ & $\mathbf{1 7 . 0}$ & $\mathbf{9 . 0}$ & $\mathbf{1 8 . 0}$ & $\mathbf{3 8 . 0}$ & $\mathbf{5 . 0}$ & $\mathbf{1 7 . 0}$ & $\mathbf{6 . 0}$ & $\mathbf{1 1 . 0}$ \\
\hline Lang et al .1989 Switzerland [7] & $\mathbf{1 3 5}$ & $\mathbf{8 8 . 0}$ & $\mathbf{2 6 . 0}$ & $\mathbf{4 . 0}$ & $\mathbf{1 0 . 0}$ & $\mathbf{1 6 . 0}$ & $\mathbf{7 . 0}$ & $\mathbf{1 3 . 0}$ & $\mathbf{7 . 0}$ & \\
\hline Chimelli et al. 1992 Rio/S.Paulo, Brazil [9] & $\mathbf{2 5 2}$ & $\mathbf{9 1 . 3}$ & $\mathbf{3 4 . 1}$ & $\mathbf{1 3 . 5}$ & $\mathbf{7 . 9}$ & $\mathbf{1 0 . 7}$ & $\mathbf{0 . 8}$ & $\mathbf{6 . 7}$ & $\mathbf{3 . 9}$ & $\mathbf{7 . 9}$ \\
\hline Wainstein et al. 1992 P. Alegre, Brazil [18] & $\mathbf{1 3 8}$ & $\mathbf{5 9 . 0}$ & $\mathbf{2 1 . 0}$ & $\mathbf{1 2 . 0}$ & $\mathbf{0}$ & $\mathbf{5 . 1}$ & $\mathbf{0}$ & $\mathbf{0}$ & $\mathbf{1 . 4}$ & $\mathbf{1 0 . 0}$ \\
\hline
\end{tabular}

(b)

\begin{tabular}{|c|c|c|c|c|c|c|c|c|c|c|c|}
\hline Post-HAART & $P$ & $N / \mathrm{NG}$ & Les & Tox & Cry & $\mathrm{CMV}$ & HIV & PML & Nod Enc & Lym & Vas \\
\hline Masliah et al. 2000 California, USA [3] & $1982-1998$ & 390 & 63 & 2.8 & 5.6 & 18.5 & 26.9 & 3.1 & $\mathbf{0}$ & 9.5 & $\mathbf{0}$ \\
\hline \multirow{4}{*}{ Jellinger et al. 2000 Austria [2] } & 1984-1999 & 450 & & & & & & & & & \\
\hline & 1984-1992 & 190 & & 24.0 & 3.1 & 17.4 & 16.1 & 5.7 & 3.1 & 6.3 & 8.8 \\
\hline & $1993-1995$ & 162 & 80.0 & 20.4 & 4.4 & 20.4 & 13.8 & 8.7 & 8.1 & 11.2 & 6.8 \\
\hline & 1996-1999 & 98 & 60.0 & 8.0 & 4.0 & 11.0 & 15.0 & 5.0 & 0 & 6.0 & 10.0 \\
\hline \multirow{4}{*}{ Morgello et al. 2002 New York, USA [20] } & 1979-2000 & 394 & 64.0 & & & & 15.0 & 1.8 & & 4.6 & \\
\hline & $1979-1986$ & 88 & 59.0 & & & & 10.0 & 4.0 & & 1.0 & \\
\hline & 1987-1995 & 207 & 58.0 & & & & 17.0 & 0 & & 5.0 & \\
\hline & $1996-2000$ & 99 & 80.0 & & & & 15.0 & 2.0 & & 7.0 & \\
\hline \multirow{5}{*}{ Neuenburg et al. 2002 Germany [21] } & 1985-1999 & 371 & 85.0 & 7.0 & 1.1 & 25.3 & 37.7 & 3.5 & & 9.4 & 12.4 \\
\hline & $1985-1986$ & 32 & & 9.4 & 3.1 & 21.9 & 34.4 & 6.3 & & 15.6 & \\
\hline & $1987-1992$ & 170 & & 7.7 & 1.2 & 35.9 & 33.5 & 1.2 & & 11.2 & \\
\hline & $1993-1995$ & 127 & & 5.5 & 0.8 & 15.7 & 37.0 & 7.1 & & 7.9 & \\
\hline & 1996-1999 & 42 & & 7.1 & 0 & 9.5 & 59.5 & 0 & & 2.4 & \\
\hline \multirow{5}{*}{ Vago et al. 2002 Italy [22] } & 1984-2000 & 1597 & & & & & 30.4 & & & & \\
\hline & $1984-1987$ & 119 & & & & & 54.0 & & & & \\
\hline & $1988-1994$ & 1116 & & & & & 32.0 & & & & \\
\hline & 1995-1996 & 256 & & & & & 18.0 & & & & \\
\hline & $1997-2000$ & 106 & & & & & 15.0 & & & & \\
\hline \multirow{4}{*}{ Gray et al. 2003 France [19] } & 1985-2002 & 343 & & & & & & & & & \\
\hline & $1985-1991$ & & & & & & & & & & \\
\hline & $1992-1996$ & & & & & & & & & & \\
\hline & $1997-2002$ & 23 & & 13.0 & 0 & 8.7 & 17.4 & 17.4 & & 13.0 & \\
\hline \multirow{3}{*}{ Walsh et al. 2004 Canada [23] } & 1985-2002 & 16 & 75.0 & 18.7 & 0 & 0 & 50.0 & 25.0 & 0 & 12.5 & 0 \\
\hline & 1 & 5 & & 60.0 & & & 60.0 & 20.0 & & 0 & \\
\hline & 2 & 11 & & 0 & & & 27.3 & 27.3 & & 18.2 & \\
\hline \multirow{4}{*}{$\begin{array}{l}\text { Silva et al. (current study) } 2011 \text { Uberaba, } \\
\text { Brazil [33] }\end{array}$} & 1989-2008 & 284 & 58.1 & 29.9 & 15.8 & 2.5 & 2.8 & 0.3 & 1.1 & 1.4 & 1.1 \\
\hline & A & 163 & 63.8 & 36.2 & 16.6 & 3.1 & 1.8 & 0.6 & 1.2 & 1.8 & 0 \\
\hline & $\mathrm{B}$ & 76 & 48.7 & 23.7 & 14.5 & 1.3 & 0 & 0 & 1.3 & 1.3 & 1.3 \\
\hline & $\mathrm{C}$ & 45 & 53.3 & 17.8 & 15.6 & 2.2 & 11.1 & 0 & 0 & 0 & 4.4 \\
\hline
\end{tabular}

$N$ : number of cases, NG: number of cases in each group; $P$ : period; the last period corresponds to HAART; Les: lesion; all lesions are expressed in percentages; Tox: toxoplasmosis; Cry: cryptococcosis, CMV: cytomegalovirus, HIV: HIV encephalitis/leukoencephalopathy; PML: progressive multifocal leukoencephalopathy JC virus; Lym: primary central nervous system non-Hodgkin lymphoma; Vas: vascular lesion (infarction, hemorrhage). Only Gray et al. Walsh et al. and the current study separated the groups by analyzing the therapy used in each patient; the others divided the groups according to treatment available at the time. 
to compare because many studies separated groups only for period, without reviewing the clinical data regarding to antiretroviral therapy (Table 3). Vago et al. [22] reported to have collected data related to treatment only in the 4 th period: $90.6 \%$ used HAART, but the length of treatment was not detailed. If we consider all patients who used HAART for any time, they constitute $38.7 \%$ ( 75 of 194) of the autopsies since 1997; however, considering the minimum duration of 3 months for the effectiveness of therapy, these cases represent only $23.2 \%$ (45 of 194) of this period. Regarding the type of lesion found, infections prevailed in all our study groups, diagnosed in $54.2 \%$ of 284 cases, much lower than that of Neuenburg et al. [21] and Vago et al. [22], which were $85 \%$ and $76 \%$, respectively; difference found perhaps due to more detailed sampling of the CNS, the routine use of immunohistochemistry for various viruses or regional differences. Considering the subtypes of infection, toxoplasmosis was the most frequent in our study as a whole (29.9\%). Unlike Masliah et al. [3], Neuenburg et al. [21] and Walsh et al. [23], whose global percentage of toxoplasmosis ranged from $2.8 \%$ to $18.7 \%$ and where HIV infections prevailed, it also occurred in pre-HAART studies from Anders et al. [5], Petito et al. [17], and Budka et al. [15], whose toxoplasmosis frequencies ranged from $6.7 \%$ to $17 \%$ and cytomegalovirus and HIV encephalitis predominated. These differences are likely to be related to environmental, geographic and socioeconomic factors. The pre-HAART Brazilians autopsy studies $[9,18]$ corroborate these ideas, as toxoplasmosis was the most frequent infection ranging from $21 \%$ to $34.1 \%$. This difference between studies in developed countries and ours also persisted in the isolated analysis of the group using HAART. In spite of the statistically significant reduction in frequency of toxoplasmosis among our untreated group, compared to the one in use of HAART (36.2\% versus $17.8 \%$ ), these values were higher than those found in studies from developed countries, in which there was reduction of $24 \%$ to $8 \%$ [2], from $9.4 \%$ to $7.1 \%$ [21], and $60 \%$ to $0 \%$ [23]. The second most common infection in our study was cryptococcosis, present in $15.8 \%$ of cases and similar in the three subgroups of this study; it was more frequent in our material, even in the HAART group $(15.6 \%)$ than in the corresponding groups from Neuenburg et al. [21], Jellinger et al. [2], and Masliah et al. [3], whose percentage ranged from 0 to $5.6 \%$. Those differences could be explained, at least in part, because many patients in our country seek medical help when already presenting with advanced neurological disease, affecting the diagnosis and treatment. Viral infections, which together represent more than $50 \%$ of lesions in the CNS studies in developed countries, even in the pre-HAART period [5, $7,15,17]$, were not common in our series, accounting for only $6.7 \%$ of 284 cases, while infections by protozoa, fungi and bacteria amounted to $49.3 \%$ in our material. HIV encephalitis occurred in $2.8 \%$ of total cases in our study, cytomegalovirus in $2.5 \%$ and JC virus infection in only $0.3 \%$. This lower percentage of viral infections in relation to other series of autopsies is probably justified due to the lower survival rates of our patients, with not enough time available for the development of HIV neuropathological lesions, complicating prior by opportunistic infections, as our patients usually seek medical treatment in advanced stages of AIDS. As to the comparison of viral infections between the groups, cytomegalovirus infection was more frequent in our group without antiretroviral drugs (3.1\%), while in the HAART group there was predominance of HIV encephalitis $(11.1 \%)$. This change is probably related to the longer survival of patients on HAART, as it has already been observed in developed countries for several years. However, the percentage of lesion by HIV was much lower, even in our HAART group, than in other series post-HAART $[2,3,19-23]$, in which it varied between $15 \%$ and $59.5 \%$. In some of these studies there was a slight reduction in HIV CNS infection over the periods studied [19, 22, 23], unlike others who showed an increase [3,21], but as mild or moderate forms. Probably the lowest frequency of HIV lesion in our HAART group, is due in part to the fact that immunohistochemistry was not performed in our study, and HIV encephalitis diagnosis was made by the direct visualization of multinucleated giant cells, unlike several of these studies that performed routine immunohistochemical as Neuenburg et al. [21], whose percentage of lesion by HIV in HAART group was $59.5 \%$. In addition to possible socioeconomic and geographic factors, in our material there was still a high frequency of toxoplasmosis and cryptococcosis, which may have slightly reduced the survival of this group of patients. Rare infections in the CNS as paracoccidioidomycosis, sporotrichosis, infection by free-living amoeba (Balamuthia mandrilares), were not reported in other studies and may be related to environmental and regional factors.

Noninfectious lesions occurred in $3.5 \%$ of our cases, also no significant difference between groups $(3.7 \%, 2.6 \%$, and $4.4 \%) ; 1.4 \%$ represented by primary CNS lymphomas and none of these cases was diagnosed premortem. In the series of Jellinger et al. [2] the frequency of this neoplasm was much higher in all time periods, ranging between $6 \%$ and $11.2 \%$, as in others post-HAART studies, which ranged from $2.4 \%$ to $18.2 \%$ [19-21, 23]. Probably because survival is higher in developed countries and frequency of opportunistic infections, lower. Important vascular lesions occurred in $4.4 \%$ of our HAART group, having been described in $10 \%$ in a corresponding group from Jellinger et al. [2] and 19.1\% in the pre-HAART study from Anders et al. [5]. They were infrequent in our study, occurred only in groups B and C, and could not be directly related to AIDS. Such large differences between the various series can be explained, at least in part, by the way we reported those lesions, as in our percentage we considered only the relevant lesions such as extensive bleeding, while Anders et al. [5] reported "bleeding of variable intensity." Given these data we can conclude that neuropathological lesions, even with the use of HAART, are still common in patients with AIDS, which is consistent with the observations reported by other authors [2, 3, 19, 21, 22].

Regarding the analysis of survival time after HIV infection diagnosis and use or not of HAART-which our study clearly demonstrated the benefit of this medicationno detailed assessment was found in the other series of autopsies, but only comments on the study from Jellinger et al. [2] and Neuenburg et al. [21], who stated that survival 
was increased after HAART. Our data confirm the concepts already well known clinically and are also in agreement with the reduction in the number of autopsies performed on AIDS after the introduction of HAART, although other factors may be involved in this issue, such as the possibility of an earlierachieved diagnosis of HIV infection.

For the correlation between clinical and autopsy findings, no similar study was found in autopsies of AIDS in relation to the CNS. Wilkes et al. [14] made a review of 101 autopsies of AIDS in pre-HAART era, comparing pre- and postmortem diagnoses in various organs; they reported that $74 \%$ of cases had lesions not suspected clinically. Another more recent study compared pre- and postmortem diagnosis in AIDS, although very detailed and classifying errors, assessed only invasive mycoses in different organs. In $36.9 \%$ of cases in which this infection was the major disease, this diagnosis was not made clinically [31]. In our series disagreement was observed in 91 (55.1\%) of 165 cases with significant lesions in the CNS (or $32 \%$ of the total 284 cases). Disagreement type 1 (important disease that if diagnosed in life could change the patient prognosis) occurred in $49(53.8 \%)$ of 91 discordant cases, representing $17.6 \%$ of the total 284 cases studied. These data demonstrate that even serious lesions are still not suspected clinically, probably because of clinical similarities and very difficult differential diagnosis, which reinforces the importance of autopsy studies to improve understanding and knowledge of brain lesions, which are common and still prevalent, even with the use HAART and the presence of advanced diagnostic technologies.

\section{Conclusions}

The present study and other series of autopsies post-HAART have shown that despite beneficial effect of HAART, the lesions in the CNS continue to be frequent and important cause of death in AIDS patients. However, the median survival time in our HAART group was four times higher compared to those without antiretroviral, which has not been evaluated in other studies of autopsies. Toxoplasmosis remained the most frequent CNS infection, despite HAART, but was less common in our HAART group $(17.8 \%$ versus $36.2 \%)$ while HIV encephalitis was more frequent (11.1\% versus $1.8 \%$ ). Nevertheless, the percentage of Brazilian toxoplasmosis is more similar to the pre-HAART studies than the post-HAART from developed countries, probably reflecting geographical or socioeconomic and cultural factors. Disagreement between the pre- and postmortem diagnosis occurred in 91 (55.1\%) of 165 cases with relevant brain lesions at autopsy; in $49(53.8 \%)$ of these 91 cases (17.2\% of the total 284 ) was disagreement type 1 : it was not diagnosed significant lesion premortem, which could change the prognosis, indicating the importance of the autopsy, even with HAART and with advanced diagnostics technologies. The reduction of type I error percentage $(62.2 \%$ until 1996 to $48.8 \%$ after 1996), may have been at least partly resulting from the knowledge acquired through the autopsy study, which was reported through anatomoclinical sessions weekly.

\section{Conflict of Interests}

The authors declare that there is no commercial or other duality of interest associated with this paper.

\section{Acknowledgments}

Financial Support was provided by Fundação de Amparo à Pesquisa do Estado de Minas Gerais (FAPEMIG- CDS 2029/2005; CDS APQ-5583-4.01/07); Conselho Nacional de Desenvolvimento Científico e Tecnológico (CNPq-Research Grant-309174/2008-2). The authors thank Alessandro Adad Jammal (medical student) for assistance in English translation and Dr. Uilho Antonio Gomes for assistance in statistical analysis.

\section{References}

[1] P. Hofman, M. C. Saint-Paul, V. Battaglione, J. F. Michiels, and R. Loubière, "Autopsy findings in the acquired immunodeficiency syndrome (AIDS). A report of 395 cases from the South of France," Pathology Research and Practice, vol. 195, no. 4, pp. 209-217, 1999.

[2] K. A. Jellinger, U. Setinek, M. Drlicek, G. Böhm, A. Steurer, and F. Lintner, "Neuropathology and general autopsy findings in AIDS during the last 15 years," Acta Neuropathologica, vol. 100, no. 2, pp. 213-220, 2000.

[3] E. Masliah, R. M. DeTeresa, M. E. Mallory, and L. A. Hansen, "Changes in pathological findings at autopsy in AIDS cases for the last 15 years," AIDS, vol. 14, no. 1, pp. 69-74, 2000.

[4] L. B. Moskowitz, J. B. Gregorios, G. T. Hensley, and J. R. Berger, "Cytomegalovirus. Induced demyelination associated with Acquired Immune Deficiency Syndrome," Archives of Pathology and Laboratory Medicine, vol. 108, no. 11, pp. 873877, 1984.

[5] K. H. Anders, W. F. Guerra, U. Tomivasu, M. A. Verity, and H. V. Vinters, "The neuropathology of AIDS. UCLA experience and review," The American Journal of Pathology, vol. 124, no. 3, pp. 537-558, 1986.

[6] L. Chimelli and S. Rosemberg, "The neuropathology of the acquired immunodeficiency syndrome (AIDS)," Revista da Sociedade Brasileira de Medicina Tropical, vol. 26, no. 2, pp. 113-119, 1993.

[7] W. Lang, J. Miklossy, J. P. Deruaz et al., "Neuropathology of the acquired immune deficiency syndrome (AIDS): a report of 135 consecutive autopsy cases from Switzerland," Acta Neuropathologica, vol. 77, no. 4, pp. 379-390, 1989.

[8] G. S. Markowitz, L. Concepcion, S. M. Factor, and A. C. Borczuk, "Autopsy patterns of disease among subgroups of an inner-city Bronx AIDS population," Journal of Acquired Immune Deficiency Syndromes and Human Retrovirology, vol. 13, no. 1, pp. 48-54, 1996.

[9] L. Chimelli, S. Rosemberg, M. D. Hahn, M. B. S. Lopes, and M. B. Netto, "Pathology of the central nervous system in patients infected with the human immunodeficiency virus (HIV): a report of 252 autopsy cases from Brazil," Neuropathology and Applied Neurobiology, vol. 18, no. 5, pp. 478-488, 1992.

[10] H. Budka, "Human immunodeficiency virus (HIV)-induced disease of the central nervous system: pathology and implications for pathogenesis," Acta Neuropathologica, vol. 77, no. 3, pp. 225-236, 1989. 
[11] H. Budka, "Cerebral pathology in AIDS: a new nomenclature and pathogenetic concepts," Current Opinion in Neurology and Neurosurgery, vol. 5, no. 6, pp. 917-923, 1992.

[12] M. C. de Almeida, L. A. Couto, L. H. da Silva, and S. S. Carvalhal, "Anatomo-clinical diagnosis correlation. Retrospective assessment of the clinical diagnosis in necropsies," Revista de Saude Publica, vol. 23, no. 4, pp. 285-291, 1989.

[13] A. N. Hui, M. N. Koss, and P. R. Meyer, "Necropsy findings in acquired immunodeficiency syndrome: a comparison of premortem diagnoses with postmortem findings," Human Pathology, vol. 15, no. 7, pp. 670-676, 1984.

[14] M. S. Wilkes, A. H. Fortin, J. C. Felix, T. A. Godwin, and W. G. Thompson, "Value of necropsy in acquired immunodeficiency syndrome," Lancet, vol. 2, no. 8602, pp. 85-88, 1988.

[15] H. Budka, G. Costanzi, S. Cristina et al., "Brain pathology induced by infection with the human immunodeficiency virus (HIV). A histological, immunocytochemical, and electron microscopical study of 100 autopsy cases," Acta Neuropathologica, vol. 75, no. 2, pp. 185-198, 1987.

[16] D. N. Lanjewar, P. P. Jain, and C. R. Shetty, "Profile of central nervous system pathology in patients with AIDS: an autopsy study from India," AIDS, vol. 12, no. 3, pp. 309-313, 1998.

[17] C. K. Petito, E. S. Cho, W. Lemann, B. A. Navia, and R. W. Price, "Neuropathology of acquired immunodeficiency syndrome (AIDS): an autopsy review," Journal of Neuropathology and Experimental Neurology, vol. 45, no. 6, pp. 635-646, 1986.

[18] M. V. Wainstein, L. Ferreira, L. Wolfenbuttel et al., "The neuropathological findings in the acquired immunodeficiency syndrome (AIDS): a review of 138 cases," Revista da Sociedade Brasileira de Medicina Tropical, vol. 25, no. 2, pp. 95-99, 1992.

[19] F. Gray, F. Chrétien, A. V. Vallat-Decouvelaere, and F. Scaravilli, "The changing pattern of HIV neuropathology in the HAART era," Journal of Neuropathology and Experimental Neurology, vol. 62, no. 5, pp. 429-440, 2003.

[20] S. Morgello, R. Mahboob, T. Yakoushina, S. Khan, and K. Hague, "Autopsy findings in a human immunodeficiency virus-infected population over 2 decades: influences of gender, ethnicity, risk factors, and time," Archives of Pathology and Laboratory Medicine, vol. 126, no. 2, pp. 182-190, 2002.

[21] J. K. Neuenburg, H. R. Brodt, B. G. Herndier et al., "HIVrelated neuropathology, 1985 to 1999: rising prevalence of HIV encephalopathy in the era of highly active antiretroviral therapy," Journal of Acquired Immune Deficiency Syndromes, vol. 31, no. 2, pp. 171-177, 2002.

[22] L. Vago, S. Bonetto, M. Nebuloni et al., "Pathological findings in the central nervous system of AIDS patients on assumed antiretroviral therapeutic regimens: retrospective study of 1597 autopsies," AIDS, vol. 16, no. 14, pp. 1925-1928, 2002.

[23] K. Walsh, W. Thompson, J. Megyesi, C. A. Wiley, and R. Hammond, "HIV-1/AIDS neuropathology in a Canadian teaching centre," Canadian Journal of Neurological Sciences, vol. 31, no. 2, pp. 235-241, 2004.

[24] T. D. Langford, S. L. Letendre, G. J. Larrea, and E. Masliah, "Changing patterns in the neuropathogenesis of HIV during the HAART era," Brain Pathology, vol. 13, no. 2, pp. 195-210, 2003.

[25] F. Gray and C. Keohane, "The neuropathology of HIV infection in the era of highly active antiretroviral therapy (HAART)," Brain Pathology, vol. 13, no. 1, pp. 79-83, 2003.

[26] S. K. Shankar, A. Mahadevan, P. Satishchandra et al., "Neuropathology of HIV/AIDS with an overview of the Indian scene," Indian Journal of Medical Research, vol. 121, no. 4, pp. 468$488,2005$.
[27] K. Kure, J. P. Llena, W. D. Lyman et al., "Human immunodeficiency virus- 1 infection of the nervous system: an autopsy study of 268 adult, pediatric, and fetal brains," Human Pathology, vol. 22, no. 7, pp. 700-710, 1991.

[28] P. W. Hunt, S. G. Deeks, B. Rodriguez et al., "Continued CD4 cell count increases in HIV-infected adults experiencing 4 years of viral suppression on antiretroviral therapy," AIDS, vol. 17, no. 13, pp. 1907-1915, 2003.

[29] M. Battegay, R. Nüesch, B. Hirschel, and G. R. Kaufmann, "Immunological recovery and antiretroviral therapy in HIV-1 infection," Lancet Infectious Diseases, vol. 6, no. 5, pp. 280-287, 2006.

[30] "Brazil-Ministério da Saúde- Secretaria de Vigilância em Saúde, Programa Nacional de DST e Aids (2008) Recomendações para Terapia Anti-retroviral em Adultos Infectados pelo HIV," 2011, http://www.ensp.fiocruz.br/portal-ensp/judicializacao/pdfs/491.pdf.

[31] S. Antinori, M. Nebuloni, C. Magni et al., "Trends in the postmortem diagnosis of opportunistic invasive fungal infections in patients with AIDS: a retrospective study of 1,630 autopsies performed between 1984 and 2002," American Journal of Clinical Pathology, vol. 132, no. 2, pp. 221-227, 2009.

[32] L. Goldman, R. Sayson, S. Robbins, L. H. Cohn, M. Bettmann, and M. Weisberg, "The value of the autopsy in three medical eras," The New England Journal of Medicine, vol. 308, no. 17, pp. 1000-1005, 1983.

[33] A. C. A. L. Silva, B. S. C. Rodrigues, E. N. M. Moura et al., "Concordância entre diagnósticos neuropatológicos premortem e postmortem em 90 pacientes com síndrome da imunodeficiência adquirida, submetidos à necropsia em um hospital de ensino no Brasil," Arquivos Brasileiros de Neurocirurgia, vol. 30, no. 3, 2011.

[34] "UNAIDS report on the global AIDS epidemic 2010AIDS scorecards," 2011, http://www.unaids.org/documents/ 20101123_AIDS_scorecards_em.pdf.

[35] J. F. De Oliveira, D. B. Greco, G. C. Oliveira, P. P. Christo, M. D. Crosland Guimarães, and R. Corrêa-Oliveira, "Neurological disease in HIV-infected patients in the era of highly active antiretroviral treatment: a Brazilian experience," Revista da Sociedade Brasileira de Medicina Tropical, vol. 39, no. 2, pp. 146-151, 2006. 


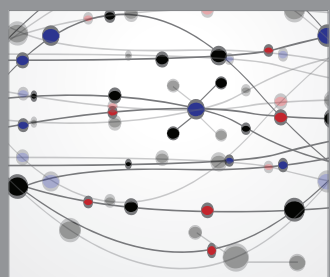

The Scientific World Journal
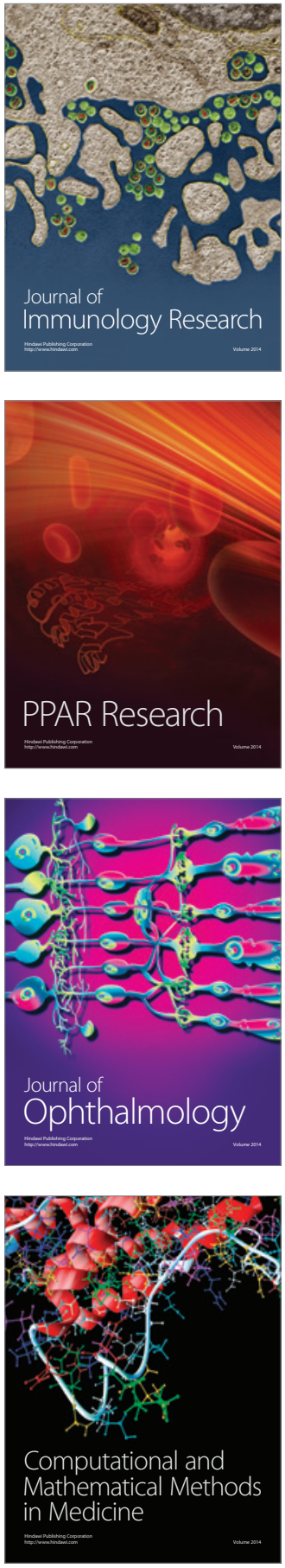

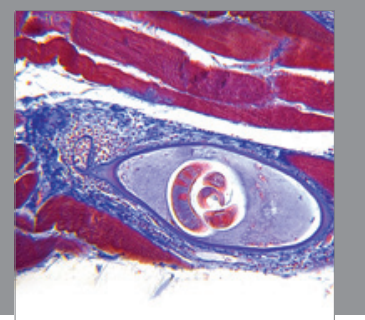

Gastroenterology

Research and Practice
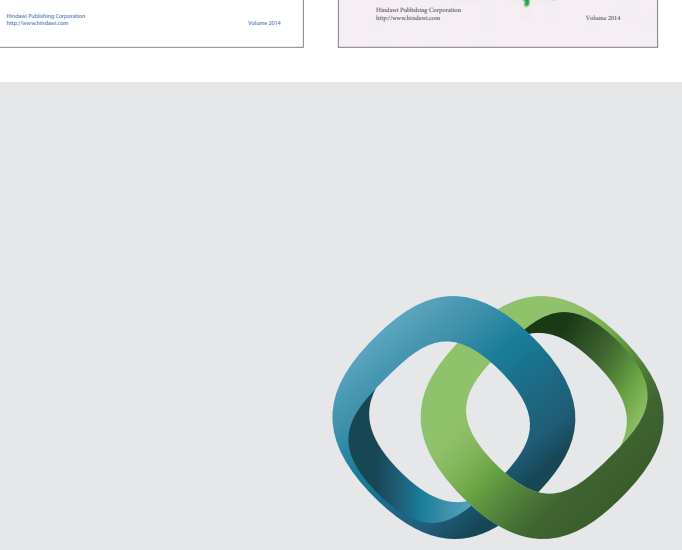

\section{Hindawi}

Submit your manuscripts at

http://www.hindawi.com
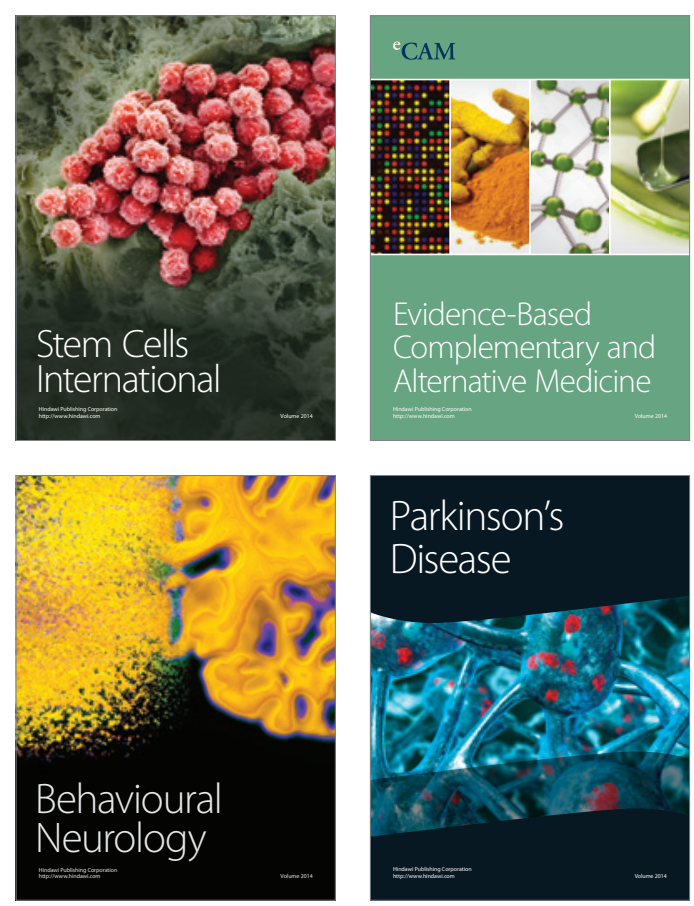

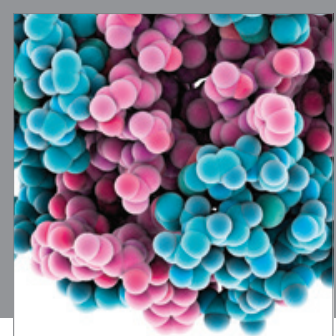

Journal of
Diabetes Research

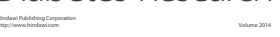

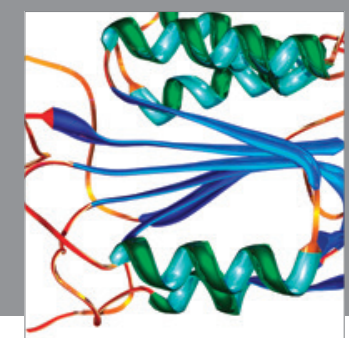

Disease Markers
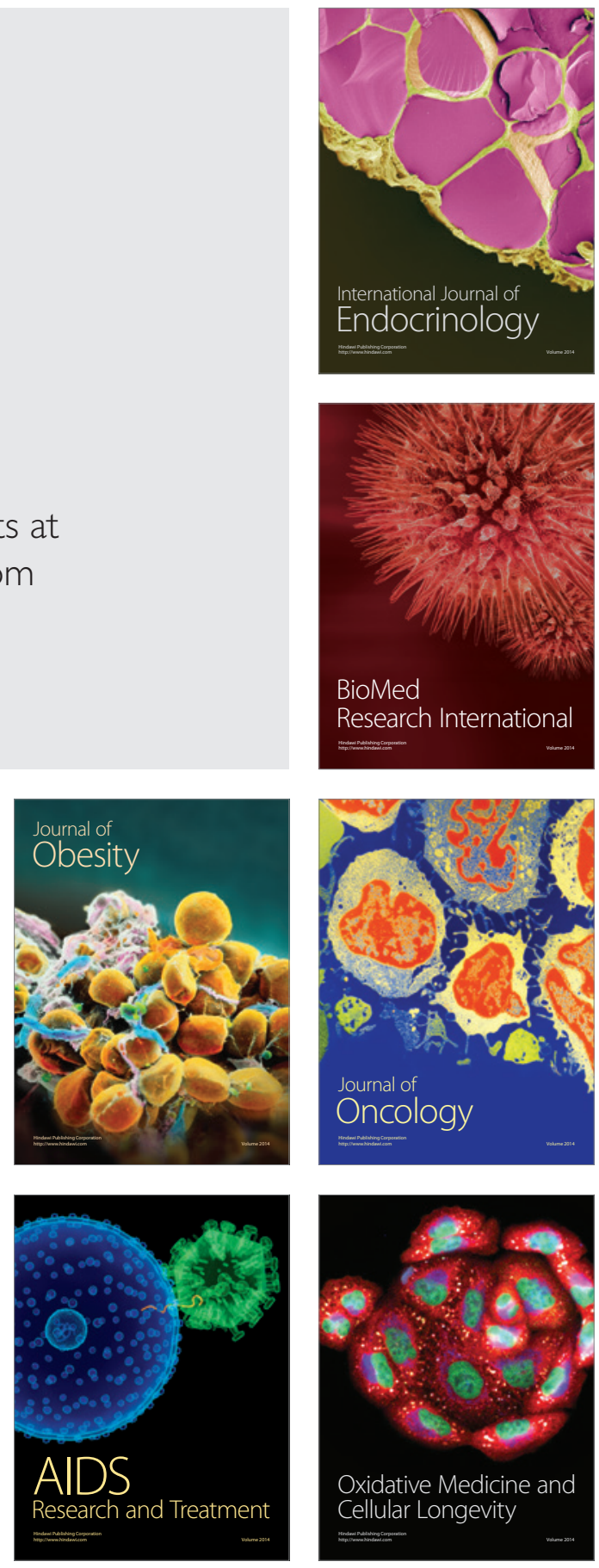